DOI: $10.20472 / E S .2016 .5 .4 .001$

\title{
POLICY UNCERTAINTY AND FOREIGN EXCHANGE RATES: THE DCC-GARCH MODEL OF THE US / JAPANESE FOREIGN EXCHANGE RATE
}

\section{KAZUTAKA KURASAWA}

\begin{abstract}
:
Since the breakdown of the Bretton Woods system in the 1970s, the US / Japan foreign exchange rate has been largely influenced by policy changes in the United States and Japan. This study applies the multivariate dynamic conditional correlation (DCC) - generalized autoregressive conditional heteroscedasticity (GARCH) models to analyze the time-varying effects of policy uncertainty, measured by the economic policy uncertainty (EPU) index of Baker et al. $(2013,2016)$, on the US / Japan foreign exchange rate. Using the EPU index as a proxy variable, it shows that the dynamic conditional correlations between policy uncertainty and the exchange rate are not time-invariant, but even sign-changing in the sample period. The analysis also empirically examined what drives the evolution of the time-varying correlations. The driving force of the correlations is, however, mostly attributed to unknown random factors.
\end{abstract}

\section{Keywords:}

policy uncertainty, foreign exchange rate, DCC model, GARCH model, time-varying correlation

JEL Classification: C32, F31

\section{Authors:}

KAZUTAKA KURASAWA, Yamanashi Gakuin University, Japan, Email: k-kurasawa@ygu.ac.jp

\section{Citation:}

KAZUTAKA KURASAWA (2016). Policy Uncertainty and Foreign Exchange Rates: The DCC-GARCH Model of the US / Japanese Foreign Exchange Rate. International Journal of Economic Sciences, Vol. V(4), pp. 1-19., 10.20472/ES.2016.5.4.001 


\section{Introduction}

In economics and finance, there is a resurgence of interest in policy uncertainty after the Global Financial Crisis and the subsequent Great Recession. Macroeconomists and financial economists have particularly focused on relationships between policy uncertainty and economic aggregates. In the literature, there are now a wide range of empirical studies analyzing the effects of policy uncertainty on economic variables. Examples include Aisen and Veiga (2013) on economic growth, Antonakakis et al. (2013) on stock market returns, Antonakakis et al. (2015) on housing market returns, Baker et al. (2015) on output, employment and investment, Balcilar et al. (2014) on inflation, and Balcilar et al. (2015) on recessions ${ }^{1}$.

Policy uncertainty is a variable that is difficult to objectively measure since it relates to expectations on how political events will unfold in the future. In the literature, recent studies applly text search methods to yield a less subjective proxy variable for policy uncertainty. Among others, Alexoupoulos and Cohen (2015), Boudoukh et al. (2013), Gentzkow and Shapiro (2010), and Hoberg and Phillips (2010) utilize information from newspaper archives, supplemented with other public sources. A team of researchers led by Baker et al. $(2013,2016)$ has also developed an index of economic policy uncertainty (EPU) based on newspaper coverage frequency, and keeps updating the index for the United States and other countries on their web site ${ }^{2}$. Many empirical studeis recently use the EPU index to measure policy uncertainty ${ }^{3}$. Although the index is not completely bias-free, it is highly correlated with major political events and other quantitative uncertainty measures, such as stock volatility indexes (Baker et al. (2016)).

Foreign exchange rates are one of potential variables that can be influenced by policy uncertainty. In econometric modeling of exchange rate, it is generally assumed that exchange rates reflect relative conditions between two countries. Differences in interest rate, price level, inflation, money, output, productivity, portfolio balances and some other risk factors are often modeled as explanatory variables ${ }^{4}$. In a similar vein, it is highly plausible that a difference in policy uncertainty between countries also affects exchange rates since risk-averse investors consider policy uncertainty as an additional risk factor. However, there have not been many studies that quantify the effects of political uncertainty on exchange rates. Only recently, Balcilar et al. (2015), Krol (2014), Martin and Urrea (2011) empirically investigate whether policy uncertainty has impact on exchange rates.

Since the breakdown of the Bretton Woods system in the early 1970s, the US / Japan exchange rate has been influenced by political events, particularly in the United States.

\footnotetext{
${ }^{1}$ Also, see Bloom (2014) for a survey of economic analysis on uncertainty

2 www.policyuncertainty.com/.

${ }^{3}$ See their web site for a list of studies using the EPU index.

${ }^{4}$ See, for example, MacDonald and Marsh (1999) for a survey.
} 
After the US government unilaterally cancelled the convertibility of the US dollar to gold in 1971, the Japanese yen sharply appreciated relative to the US dollar. In the early 1980s, the yen gradually depreciated due to the tight monetary policy and the Volker disinflation in the United States, and then reversed its course in the aftermath of the Plaze accord in 1985. In the early 1990, when the Clinton administration took a tough stand against Japan to reduce the US current accound deficit, the Japanese yen reached a high point in 1995. After a relatively stable decade, the yen hit a new record high in 2012 after the Global Financial Crisis. In more recent years, the Federal Reserve Board and the Bank of Japan have implemented unconventional measures of monetary policy to help bolster domestic demand. The "fiscal cliff" in the United States and the soaring public debt in Japan have also raised questions of solvancy and sustainability. These unprecedented and uncertain situations have triggered market jitters in the foreign exchange market in the mid-2010s ${ }^{5}$.

The annecdotal evidence appears to indicate that anticipated and unanticipated policy changes have nonnegligible effects on the foreign exchange rate. The forward-looking market is expected to factor in policy uncertainty in the United States and Japan. However, it is yet to be confirmed by statistical analysis whether the exchange rate has been driven by policy uncertainty.

This paper analyzes the effects of policy uncertainty measured by the EPU index on the US / Japan exchange rate, using the multivariate dynamic conditional correlation (DCC) generalized autoregressive conditional heteroscedasticity (GARCH) model. The DCCGARCH model has been developed by Engle (2002) and Tse and Tsui (2002), and widely used in macroeconomic and financial applications to take account for time-varying conditional heteroscedasticity in multivariate time series. In macroeconomic and financial time series, correlations are often time-variant and even sign-changing. The DCC-GARCH model formulates a heteroscedastic process of a covariance matrix such that conditional correlations are time-dependent and governed by a small number of parameters. This parsimonious model generates efficient estimates that describe time-variant correlational structures between variables.

One of possible alternatives to measure the time-varying correlation is rolling regression. It is, however, highly likely that the estimator of rolling regression is biased since the length of the rolling window is arbitrarily set and rolling regression measures effects that may have long disappeared. This is called the "ghost" effect in the econometric literature. Without setting the length of the rolling window, the $\mathrm{DCC}-\mathrm{GARCH}$ model reduces the estimation bias.

\footnotetext{
${ }^{5}$ Volker and Gyoten (1992) document these events from a point of view of policymakers.
} 
Evaluating the correlations between policy uncertainty, inflation and output in the United States, Jones and Olson (2012) find that the sign of the correlation between uncertainty and inflation has changed in their sample period while the correlation between uncertainty and output is consistently negative. This finding indicates that time-invariant correlation between policy uncertainty and other variables should not be assumed a priori, but models that can accommodate both synchronous and asynchronous periods should be used. From a similar point of view, this paper applies the DCC-GARCH model to the US / Japan exchange rate and investigates the extent of possible time-varying effects of policy uncertainty on the exchange rate.

The remainder of the paper is organized as follows. Section 2 presents the two types of the DCC-GARCH models - the models of Engle (2002) and Tse and Tsui (2002). Section 3 describes the data used in this study. Section 4 reports the empirical results from the models. Section 5 investigates what determines the signs and magnitudes of the timevarying correlations. Regression analysis is performed with policy uncertainty and general economic conditions as explanatory variables. The last section concludes.

\section{The GARCH-DCC Model}

This study considers a vector of three variables $y_{t}=\left[y_{1 t}, y_{2 t}, y_{3 t}\right]$, where $y_{1 t}$ and $y_{2 t}$ are the EPU indexes that measure economic policy uncertainty in the United States and Japan, and $y_{3 t}$ is the US / Japan foreign exchange rate, in either level or first difference, at time t. The exchange rate is defined as Japanese yen per US dollar. Let $e_{t}$ a vector of error terms. Then, the model has the form

$$
\begin{aligned}
& y_{t}=\mu+e_{t} \\
& e_{t} \mid \Omega_{t-1} \sim t_{v}\left(0, \Sigma_{t}\right) \\
& \Sigma_{t}=D_{t} \rho_{t} D_{t}
\end{aligned}
$$

where $\mu_{t}$ is a vector of unconditional means, $\Sigma_{t}=\left[\sigma_{i j, t}\right]$ is the time-variant covariance matrix of $e_{t}, D_{t}=\operatorname{diag}\left\{\sigma_{11, t}^{1 / 2}, \sigma_{22, t}^{1 / 2} \sigma_{33, t}^{1 / 2}\right\}$ is the diagonal matrix of the variances, and $\rho_{t}$ is the conditional correlation matrix. $e_{t}$ is assumed to follow the multivariate Student $t$ distribution with $v$ degrees of freedom given the information available at time $t-1$, or $\Omega_{t-1}$. The Student $t$ distribution is used to handle possible fat tails in the exchange rate.

\footnotetext{
${ }^{6}$ Notice that the variance is denoted as $\sigma_{i i, t}$ in the variance-covariance matrix $\Sigma_{t}$. Thus, $\sigma_{i i, t}^{1 / 2}$ refers to the standard deviation.
} 
Engle (2002) proposes the DCC model that formulates the evolution of $\rho_{t}$ as

$$
\begin{aligned}
Q_{t}= & \left(1-\theta_{1}-\theta_{2}\right) \bar{Q}+\theta_{1} Q_{t-1}+\theta_{2} \eta_{t-1} \eta_{t-1} \\
& \rho_{t}=J_{t} Q_{t} J_{t}
\end{aligned}
$$

where $\eta_{t}=\left[\eta_{1 t}, \eta_{2 t}, \eta_{3 t}\right]^{\prime}$ is a vector of the marginally standardized errors $\eta_{i t}=e_{i t} / \sqrt{\sigma_{i i, t}}$, , $\bar{Q}$ is the unconditional covariance matrix of $\eta_{t}, J_{t}=\operatorname{diag}\left\{\rho_{11, t}^{-1 / 2}, \rho_{22, t}^{-1 / 2}, \rho_{33, t}^{-1 / 2}\right\}$ is the diagonal matrix of $Q_{t}, \theta_{1}$ and $\theta_{2}$ are fixed coefficients ${ }^{7}$.

Tse and Tsui (2002) propose an alternative specification:

$$
\rho_{t}=\left(1-\theta_{1}-\theta_{2}\right) \bar{\rho}+\theta_{1} \rho_{t-1}+\theta_{2} \varphi_{t-1}
$$

where $\varphi_{\mathrm{t}}$ is a local correlation matrix of $\left\{\eta_{1}, \ldots, \eta_{t-m}\right\}$ for some positive integer $\mathrm{m}$. Notice that the dynamics of $Q_{t}$, and $\rho_{t}$ are governed by the two parameters $\theta_{1}$ and $\theta_{2}$ in (4) and (6).

In what follows, the DCC-GARCH models are estimated in two steps. The residual series $\hat{e}_{t}=y_{t}-\hat{\mu}$ are first computed and used to estimate univariate GARCH models. Then, the DCC models are fitted to $\widehat{\eta_{l t}}=\widehat{e_{l t}} / \sqrt{\widehat{\sigma_{l, t}}}$ and $\hat{\varphi}_{t}$, a sample correlation matrix estimated from $\left\{\hat{\eta}_{1}, \ldots, \hat{\eta}_{t-m}\right\}$ for a predetermined $\mathrm{m}$.

\section{Data}

Baker et al. $(2013,2016)$ have developed a monthly EPU index that measures policyrelated economic uncertainty. The index is based on the relative frequency of key words that appear in newspapers. This study uses the EPU index as a proxy variable for economic policy uncertainty.

For the United States, the monthly EPU index is constructed from three components: news coverage, federal tax code expiration data, and economic forecaster disagreement. The first component of the EPU index reflects how many articles contain the triple of key words - (1) "economic" or "economy", (2) "uncertain" or "uncertainty", and (3) one or more of "deficit", "Federal Reserve", "legislation", "regulation" or "White House" - in ten leading newspapers. The second component utilizes the Congressional Budget Office (CBO)'s reports that list the expiration dates of temporary federal tax provisions, assuming that temporary tax measures create uncertainty for businesses and households. The third component draws upon the Federal Reserve Bank of Philadelphia's Survey of Professional

\footnotetext{
${ }^{7} Q_{t}$ is a positive-definite matrix and $J_{t}$ is a normalization matrix.
} 
Forecasters, measuring the dispersion in the forecasts of the consumer price index (CPI) and the purchases of goods and services by the federal, state and local governments. After these components are individually collected each month and indexed over the period starting in January of 1985, the monthly economic policy uncertainty index is constructed by aggregating the components. Technical details are explained in Baker et al. (2016), and the data sets are downloaded from their web site.

Figure 1 plots the US EPU index in the period from January 1994 to April 2016, which this study covers. The figure displays the oveall index constructed from the three components aa well as the index based only on newspaper coverage. The overall and newpaper coverage indexes co-move closely with each other in the sample period. The oveall index shows spikes around the September 11 attack in 2001, the invasion of Iraq in 2003, the Global Financial Crisis of 2007-2008 and the subsequent Great Recession.

\section{Figure 1: The US EPU Index}

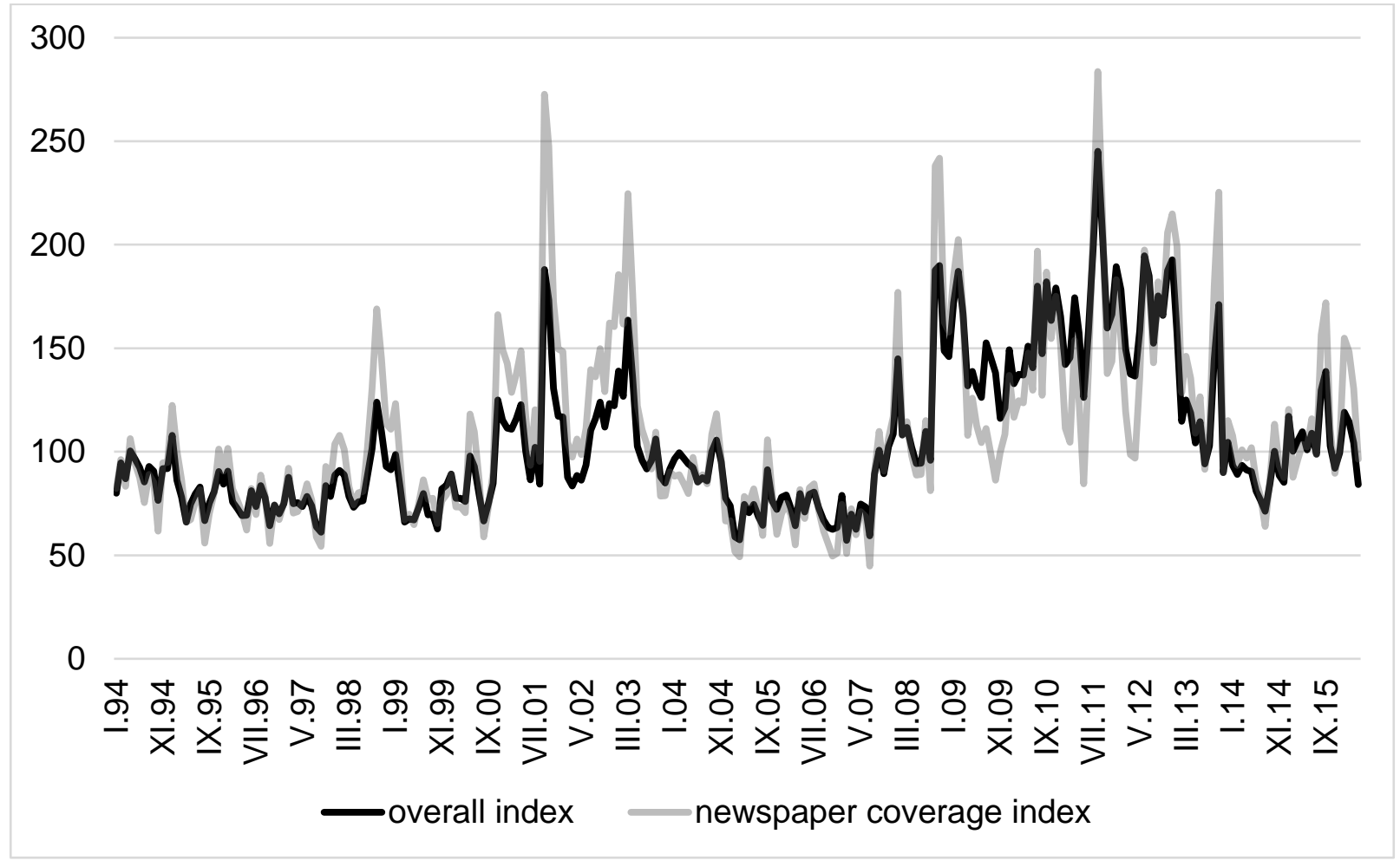

Source: Baker et al. (2016) and and their web site.

For Japan, the index starts in January $1994^{8}$. The Japanese index is constructed from the frequency count of articles containing the Japanese equivalents of the three key words in

${ }^{8}$ After writing this draft, the website published the new series of the Japanese EPU index starting back in 1988. 
two largest newspapers. The index shows spikes around the domestic banking crisis and the Asian financial crisis in 1997-98, the Global Financial Crisis of 2007-08 and the recent Great Recession. It also exceeds a 150 level in Januaries of the late 1990s; the Japanese governemnt begins deliberations on the government budget in January, and it faced tough fiscal decisions during the economic slump of the late 1990s. The Japanese index is still the "beta" nature, drawing only on newspaper coverage. Given that the US newspaper coverage index is closely correlated with the overall index, however, the Japanese index can be used as an acceptable proxy variable for policy uncertainty

Figure 2: The Japanese EPU Index

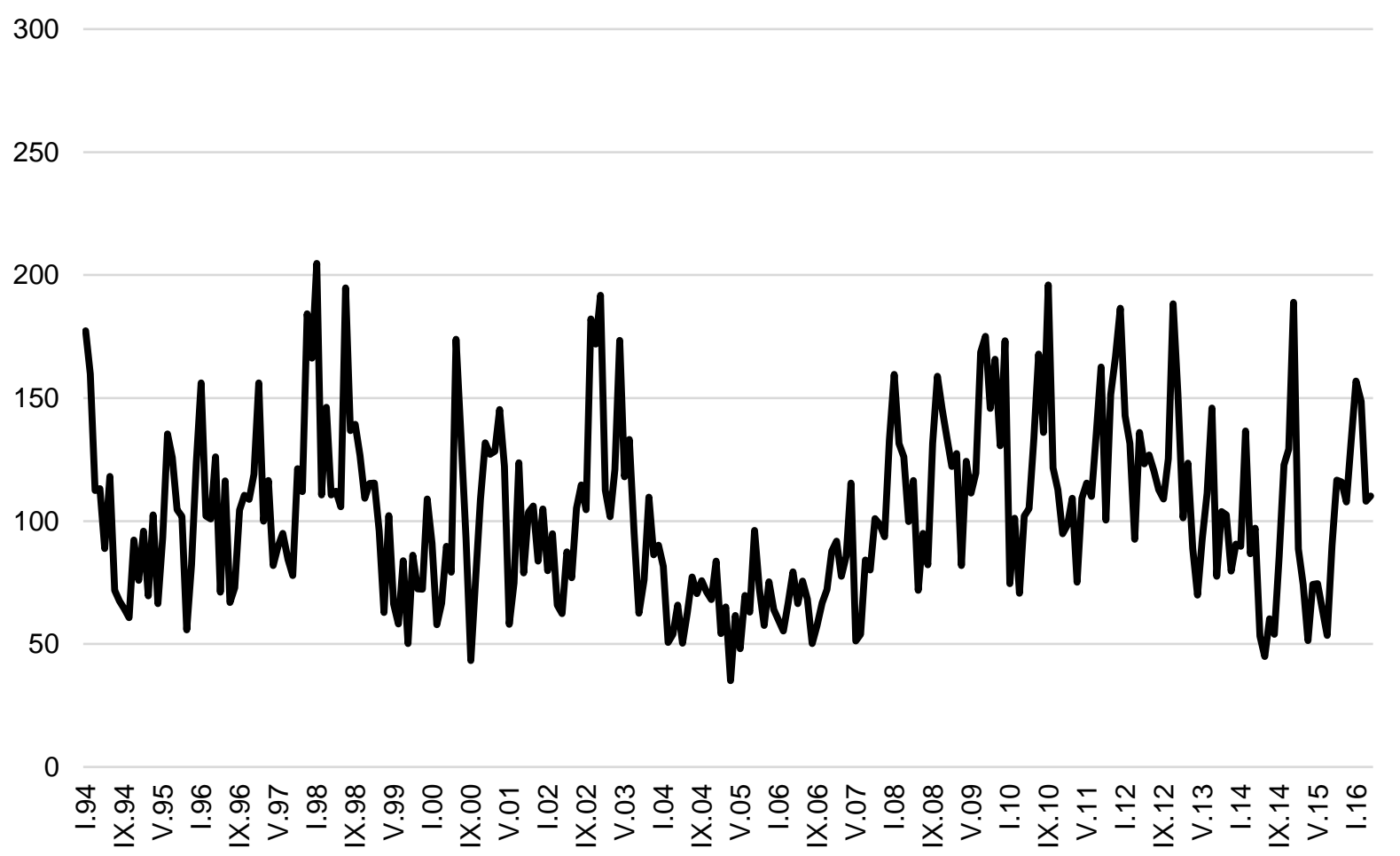

Source: Baker et al. (2016) and and their web site.

The US / Japan foreign exchange rate is sourced from the FRED database of the Federal Reserve Bank of St. Louis ${ }^{9}$. The series is the monthly average of daily noon rates in New York City for cable transfers payable in the Japanese yen. Figure 3 plots the exchange rate, along with the US and Japanese EPU indexes. The correlation between the exchange rate and the EPU indexes does not appear time-invariant. Also, notice that the US and Japanese EPU indexes are highly corrlated with each other after 2000; the invatsion of Irqa

${ }^{9}$ fred.stlouisfed.org. 
by the United States and the Global Financial Crisis were global shocks that hit the US and Japanese governments simultaneously.

The analysis below covers the sample period ranging from January 1994, when the Japanese EPU index starts, through April 2016. The serieses are all log-transformed. The level and first-difference of the exchange rate are both analyzed as $y_{3, t}$. Table 1 reports descriptive statistics for the variables in logarithm. The unconditional correlations between the US index and the level of the exchange rate are negative and relatively high in absolute value. The correlation between the uncertainty indexes indicates a moderate positive relationship of the US and Japanese uncertainty. The other estimated correlations are weak.

Figure 3: The US / Japan Exchange Rate and the EPU Indexes

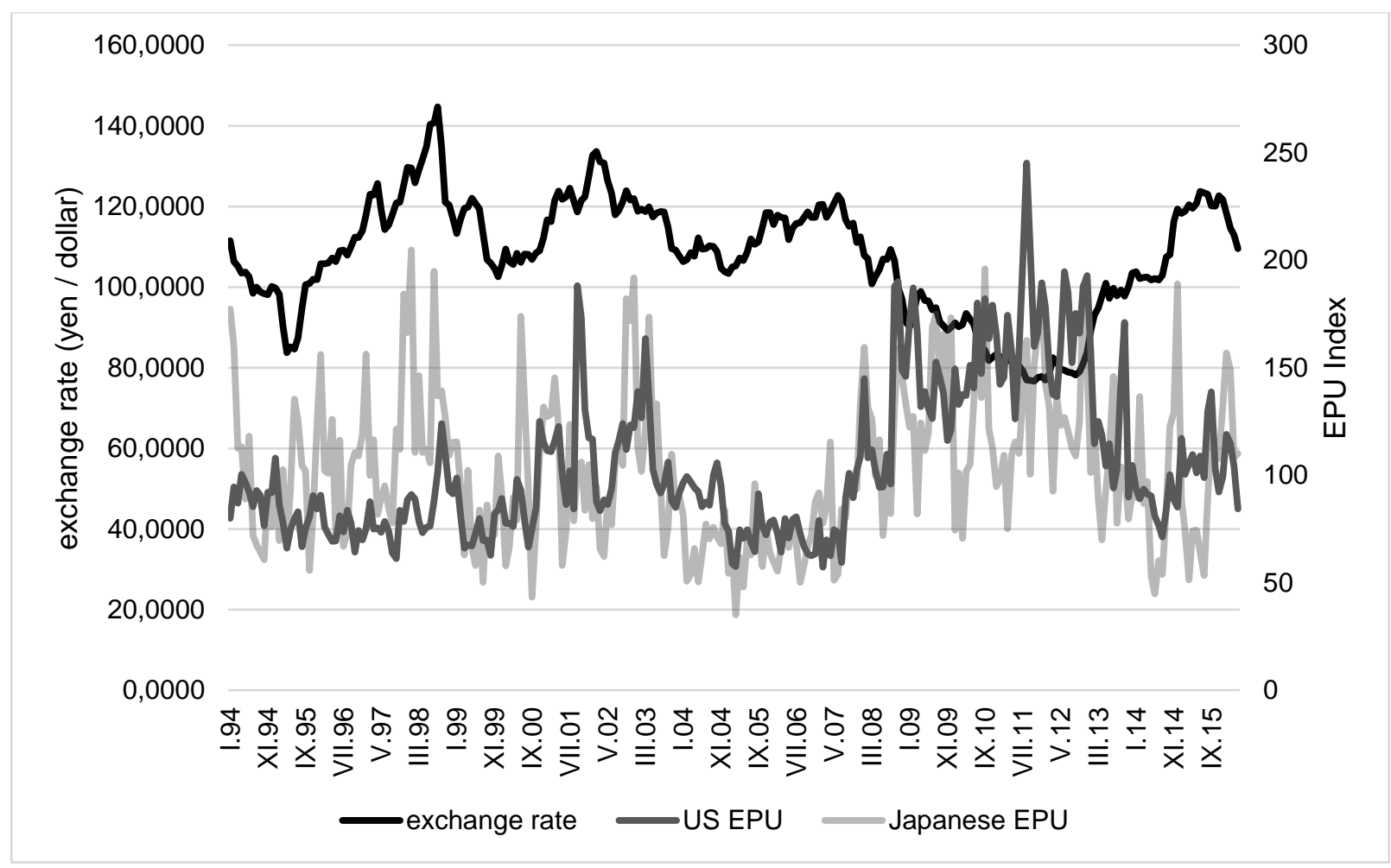

Source: The FRED of the Federal Reserve Bank of St. Louis

Table 1: Descriptive Statistics

\begin{tabular}{l|l|l|l|l}
\hline & US Index & $\begin{array}{l}\text { Japanese } \\
\text { Index }\end{array}$ & $\begin{array}{l}\text { Exchange Rate } \\
\text { (level) }\end{array}$ & $\begin{array}{l}\text { Exchange Rate } \\
\text { (1st difference) }\end{array}$ \\
\hline Minimum & 4.0466 & 3.5583 & 4.3392 & -0.1052 \\
\hline Mean & 4.6072 & 4.5747 & 4.6678 & -0.0001 \\
\hline
\end{tabular}




\begin{tabular}{l|l|l|l|l} 
Maximum & 5.5018 & 5.3217 & 4.9745 & 0.0807 \\
\hline $\begin{array}{l}\text { Standard } \\
\text { Deviation }\end{array}$ & 0.3098 & 0.3446 & 0.1398 & 0.0263 \\
\hline
\end{tabular}

\section{Unconditional Variance-Covariance}

\begin{tabular}{l|l|l|l|l}
\hline & US Index & $\begin{array}{l}\text { Japanese } \\
\text { Index }\end{array}$ & $\begin{array}{l}\text { Exchange Rate } \\
\text { (level) }\end{array}$ & $\begin{array}{l}\text { Exchange Rate } \\
\text { (1st difference) }\end{array}$ \\
\hline US Index & 0.0956 & & & \\
\hline Japanese Index & 0.0519 & 0.1183 & & 0.0007 \\
\hline $\begin{array}{l}\text { Exchange Rate } \\
\text { (level) }\end{array}$ & -0.0240 & -0.0094 & 0.0195 & \\
\hline $\begin{array}{l}\text { Exchange Rate } \\
\text { (1st difference) }\end{array}$ & -0.0009 & -0.0004 & n.a. & \\
\hline
\end{tabular}

\section{Unconditional Correlation}

\begin{tabular}{l|l|l|l|l}
\hline & US Index & $\begin{array}{l}\text { Japanese } \\
\text { Index }\end{array}$ & $\begin{array}{l}\text { Exchange Rate } \\
\text { (level) }\end{array}$ & $\begin{array}{l}\text { Exchange Rate } \\
\text { (1st difference) }\end{array}$ \\
\hline US Index & 1.0000 & & & \\
\hline $\begin{array}{l}\text { Japanese } \\
\text { Index }\end{array}$ & 0.4880 & 1.0000 & & \\
\hline $\begin{array}{l}\text { Exchange Rate } \\
\text { (level) }\end{array}$ & -0.5556 & -0.1967 & 1.0000 & 1.0000 \\
\hline $\begin{array}{l}\text { Exchange Rate } \\
\text { (1st difference) }\end{array}$ & -0.1121 & -0.0458 & n.a. & \\
\hline
\end{tabular}

Source: Own Calculation

\section{$4 \quad$ Empirical Results}

Using the residual series $\hat{e}_{t}=y_{t}-\hat{\mu}$, univariate $\mathrm{GARCH}$ models are estimated by maximizing the log-likelihood functions. GARCH $(1,1)$ is specified for simplicity. The $\operatorname{GARCH}(1,1)$ models have the form

$$
\sigma_{i i, t}=\gamma_{0}+\gamma_{1} e_{i, t-1}^{2}+\gamma_{2} \sigma_{i i, t-1}
$$

for $\mathrm{i}=1,2$ and 3 . Table 2 reports the estimated coefficients, standard errors and $\mathrm{t}$-values.

Table 2: The GARCH $(1,1)$ Models

\begin{tabular}{l|l|l|l|l|l|l|l|l}
\hline & \multicolumn{9}{l|}{ Level } & \multicolumn{1}{l}{ 1st Difference } \\
\hline & & $\gamma 0$ & $\gamma 1$ & $\gamma 2$ & & $\gamma 0$ & $\gamma 1$ & $\gamma 2$ \\
\hline \multirow{3}{*}{ US Index } & estimate & 0.0739 & 0.2140 & 0.1631 & estimate & 0.0724 & 0.2075 & 0.1778 \\
\cline { 2 - 8 } & $\begin{array}{l}\text { standard } \\
\text { error }\end{array}$ & 0.0261 & 0.1027 & 0.2347 & $\begin{array}{l}\text { standard } \\
\text { error }\end{array}$ & 0.0261 & 0.1014 & 0.2376 \\
\hline
\end{tabular}




\begin{tabular}{l|l|l|l|l|l|l|l|l} 
& $\mathrm{t}$-value & 2.8303 & 2.0830 & 0.6950 & $\mathrm{t}$-value & 2.7713 & 2.0458 & 0.7483 \\
\hline \multirow{3}{*}{$\begin{array}{l}\text { Japanese } \\
\text { Index }\end{array}$} & estimate & 0.0232 & 0.8102 & 0.0000 & estimate & 0.0232 & 0.8118 & 0.0000 \\
\cline { 2 - 9 } & $\begin{array}{l}\text { standard } \\
\text { error }\end{array}$ & 0.0054 & 0.1634 & 0.1111 & $\begin{array}{l}\text { standard } \\
\text { error }\end{array}$ & 0.0054 & 0.1629 & 0.1097 \\
\cline { 2 - 9 } & t-value & 4.2731 & 4.9584 & 0.0000 & t-value & 4.2686 & 4.9834 & 0.0000 \\
\hline \multirow{3}{*}{$\begin{array}{l}\text { Exchange } \\
\text { Rate }\end{array}$} & estimate & 0.0006 & 0.9726 & 0.0000 & estimate & 0.0005 & 0.2395 & 0.0562 \\
\cline { 2 - 9 } & $\begin{array}{l}\text { standard } \\
\text { error }\end{array}$ & 0.0002 & 0.2416 & 0.2082 & $\begin{array}{l}\text { standard } \\
\text { error }\end{array}$ & 0.0002 & 0.0965 & 0.2258 \\
\cline { 2 - 9 } & t-value & 3.1139 & 4.0261 & 0.0000 & t-value & 2.9028 & 2.4833 & 0.2489 \\
\hline
\end{tabular}

Source: Own Calculation

For all the variables, the estimates of $\gamma_{2}$ are almost nil or negligibly small, indicating that the volatilities are not persistent in the GARCH processes.

\section{Table 3: The DCC Models}

\begin{tabular}{|c|c|c|c|c|c|c|}
\hline \multirow[t]{2}{*}{ Engle } & \multicolumn{3}{|l|}{ Level } & \multicolumn{3}{|c|}{ 1st Difference } \\
\hline & $\theta 1$ & $\theta 2$ & d.f. & $\theta 1$ & $\theta 2$ & d.f. \\
\hline estimate & 0.8902 & 0.0800 & 20.0000 & 0.7884 & 0.0800 & 20.0000 \\
\hline standard error & 0.0189 & 0.0139 & 5.4878 & 0.1999 & 0.0518 & 6.2493 \\
\hline t-value & 47.1848 & 5.7519 & 3.6445 & 3.9448 & 1.5446 & 3.2004 \\
\hline & \multicolumn{2}{|c|}{ test statistic } & $p$-value & \multicolumn{2}{|c|}{ test statistic } & $p$-value \\
\hline $\begin{array}{l}\text { Lagrange } \\
\text { multiplier }\end{array}$ & \multicolumn{2}{|l|}{17.6546} & 0.0611 & \multicolumn{2}{|c|}{13.9528} & 0.1752 \\
\hline Lijung-Box & \multicolumn{2}{|l|}{14.4579} & 0.1531 & \multicolumn{2}{|l|}{12.3214} & 0.2641 \\
\hline $\begin{array}{l}\text { Lijung-Box } \\
\text { (robust) }\end{array}$ & \multicolumn{2}{|c|}{105.4782} & 6 & \multicolumn{2}{|l|}{77.7903} & 71 \\
\hline Rank-based & \multicolumn{2}{|c|}{122.6093} & 0.0127 & \multicolumn{2}{|l|}{77.6219} & 0.8208 \\
\hline
\end{tabular}

\begin{tabular}{l|l|l|l|l|l|l}
\hline & \multicolumn{4}{|l|}{ Level } & \multicolumn{3}{l}{ 1st Difference } \\
\hline & $\theta 1$ & $\theta 2$ & d.f. & $\theta 1$ & $\theta 2$ & d.f. \\
\hline estimate & 0.4000 & 0.0664 & 20.0000 & 0.4000 & 0.0800 & 20.0000 \\
\hline standard error & 0.3875 & 0.0514 & 4.8452 & 0.2799 & 0.0570 & 5.8354 \\
\hline t-value & 1.0324 & 1.2913 & 4.1278 & 1.4292 & 1.4024 & 3.4274 \\
\hline
\end{tabular}

\begin{tabular}{l|l|l|l|l}
\hline & test statistic & $p$-value & test statistic & $p$-value \\
\hline $\begin{array}{l}\text { Lagrange } \\
\text { multiplier }\end{array}$ & 11.9645 & 0.2874 & 11.6245 & 0.3110 \\
\hline $\begin{array}{l}\text { Lijung-Box } \\
\begin{array}{l}\text { Lijung-Box } \\
\text { (robust) }\end{array}\end{array}$ & 16.0426 & 0.0984 & 12.2559 & 0.2683 \\
\hline
\end{tabular}




\begin{tabular}{lllll} 
Rank-based & 123.0179 & 0.0119 & 89.6647 & 0.4901 \\
\hline Source: Own Calculation &
\end{tabular}

From the GARCH models estimated above, $\widehat{\eta_{l t}}=\widehat{e_{l t}} / \sqrt{\widehat{\sigma_{l, t}}}$ are computed and used to fit the DCC models. Table 3 reports the estimated coefficients $\hat{\theta}_{1}$ and $\hat{\theta}_{2}$ from the maximum likelihood estimation. The estimated degree of freedom for the multivariate Student $t$ distribution is also reported in the table. The conditions $0<\hat{\theta}_{1}+\hat{\theta}_{2}<1$ are all satisfied, which confirms the stability of the DCC processes. For the Engle model with the level of the exchange rate, the parametric estimates $\hat{\theta}_{1}$ and $\hat{\theta}_{2}$ are both significant at the $1 \%$ level. For the other models, the estimates are all insignificant except for $\hat{\theta}_{1}$ in the Engle model. The degree of freedom for the multivariate Student-t distribution is estimated to be 20.00 with standard errors 4.85-6.25, which indicates fat tails.

The diagnostic statistics are also reported in Table $4^{10}$. Under the null hypothesis that the series have no additional heteroscedasticity, the robust portmanteau test rejects the Engle model at the $5 \%$ significance for the level. The Tse and Tsui model is also rejected by the two portmanteau tests. For the first difference, no diagnostic statistics reject the models. The diagnostic tests indicate that these models fit the data relatively well since the diagnostic tests typically reject a fitted DCC model (Tsay (2013)).

Figures 4.1-4 display the evolutions of the estimated dynamic conditional correlation coefficients $\hat{\rho}_{13, t}$ and $\hat{\rho}_{23, t}$. The two models generate similar sequences of positive and negative correlations although the Engle model has stronger persistence and larger values in the time-varying correlations.

For the levels, the dynamic correlations are neither consistently positive nor negative throughout the sample period. Some regularities are, however, observed. The correlations between the exchange rate and the US index remains negative in the late 2000 s. The negative correlation is expected since rising policy uncertainty in the United States should lower the value of the US dollar, or more stable policy environments in the United States should raise the US dollar vis-à-vis the Japanese yen. The correlation coefficients are, however, positive and relatively high in the late 1990s and the early 2000 s.

The correlations of the Japanese index are neither consistently positive nor negative. In 1997-98, when the Japanese economy was hit by the Asian Financial Crisis and the domestic banking panic, the correlations are moderately positive. The positive correlation is in line with the expectation that Japanese policy uncertainty pushes down the value of

\footnotetext{
10 Three portnanteau tests are performed for heteroscedasticity: the Lagrange multiplier test of Engle (1982), the LjungBox test of Ljung and Box (1978) and the robust version of the Ljung-Box test with $5 \%$ upper tail trimming. A rankbased test of Dufour and Roy $(1985,1986)$ is also performed. See Tsay $(2013)$ for technical details.
} 
the Japanese yen. The correlations are, on the other hand, moderately negative throughout the period 2006-13, when the Japanese uncertainty index is relatively high.

For the first differences, the estimated coefficients do not have noticeable clusters of positive or negative correlations. The correlations of the US index are close to zero throughout the sample period. The correlations of the Japanese index are small, but consistently negative, which is at odds with the commonly held assumption that a country's political uncertainty is expected to lower the value of its currency.

Figure 4.1: The Dynamic Conditional Correlation (Level, Engle)

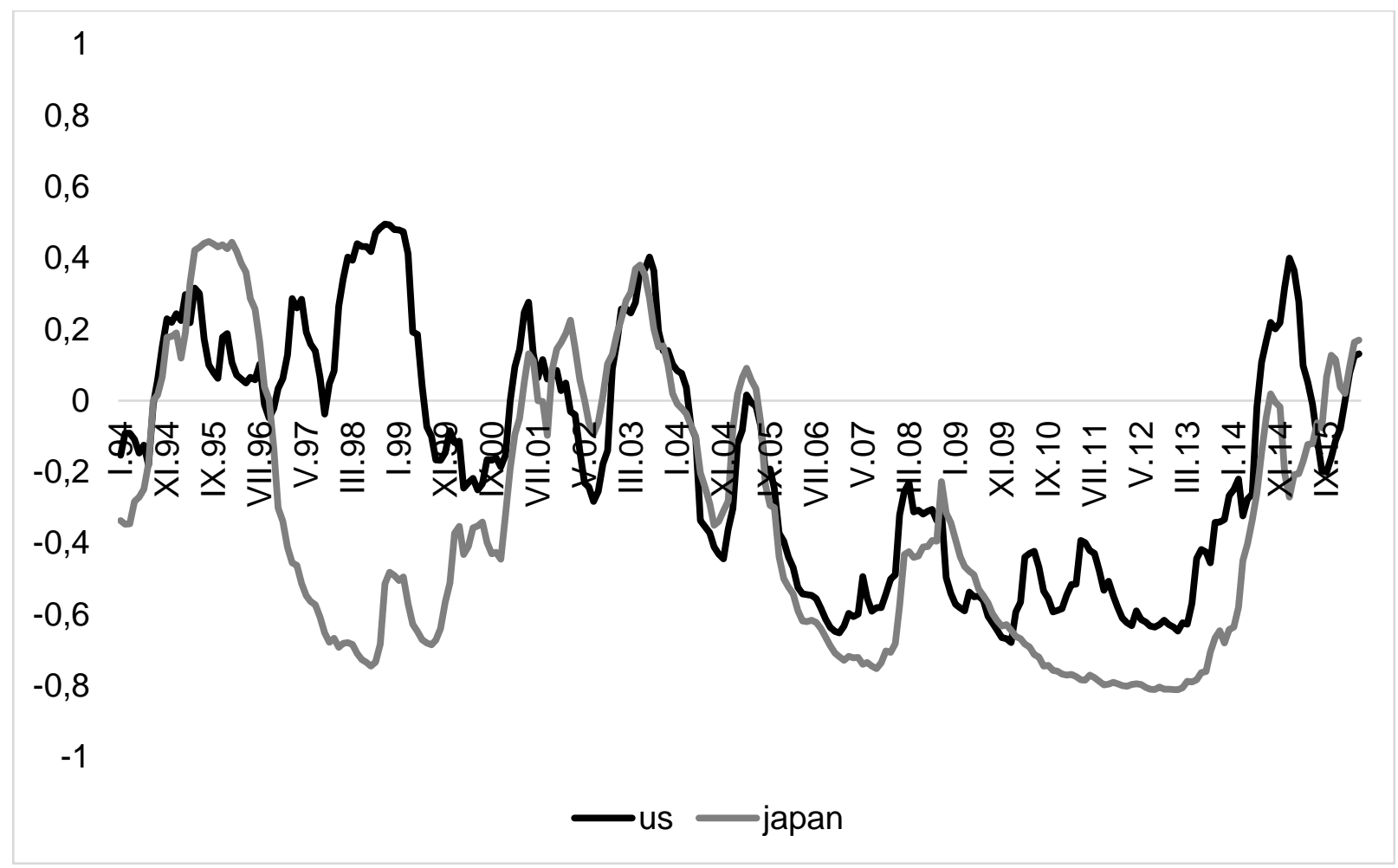


Figure 4.2: The Dynamic Conditional Correlation (Lelel, Tse and Tsui)

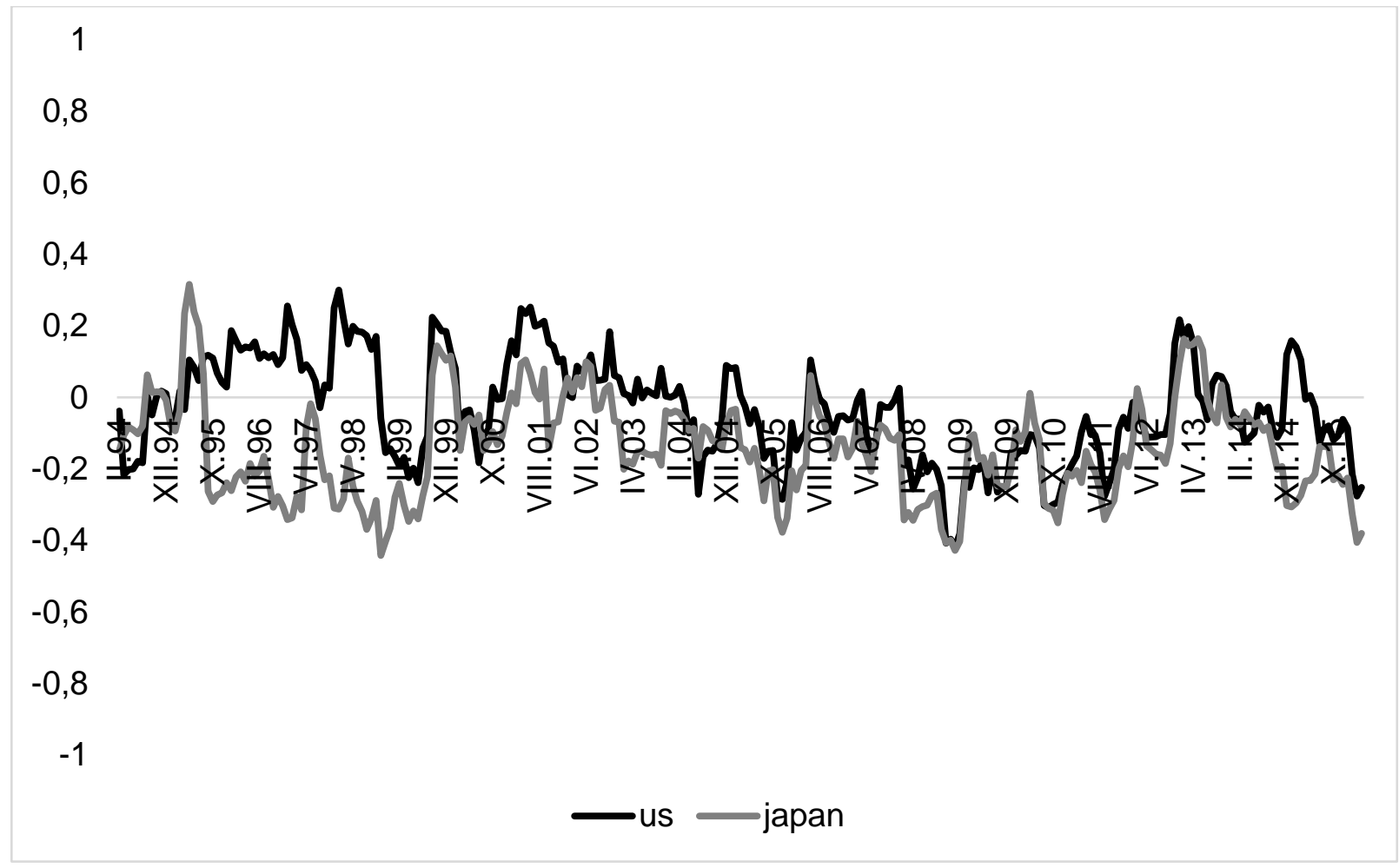

Figure 4.3: The Dynamic Conditional Correlation (1st Difference, Engle)

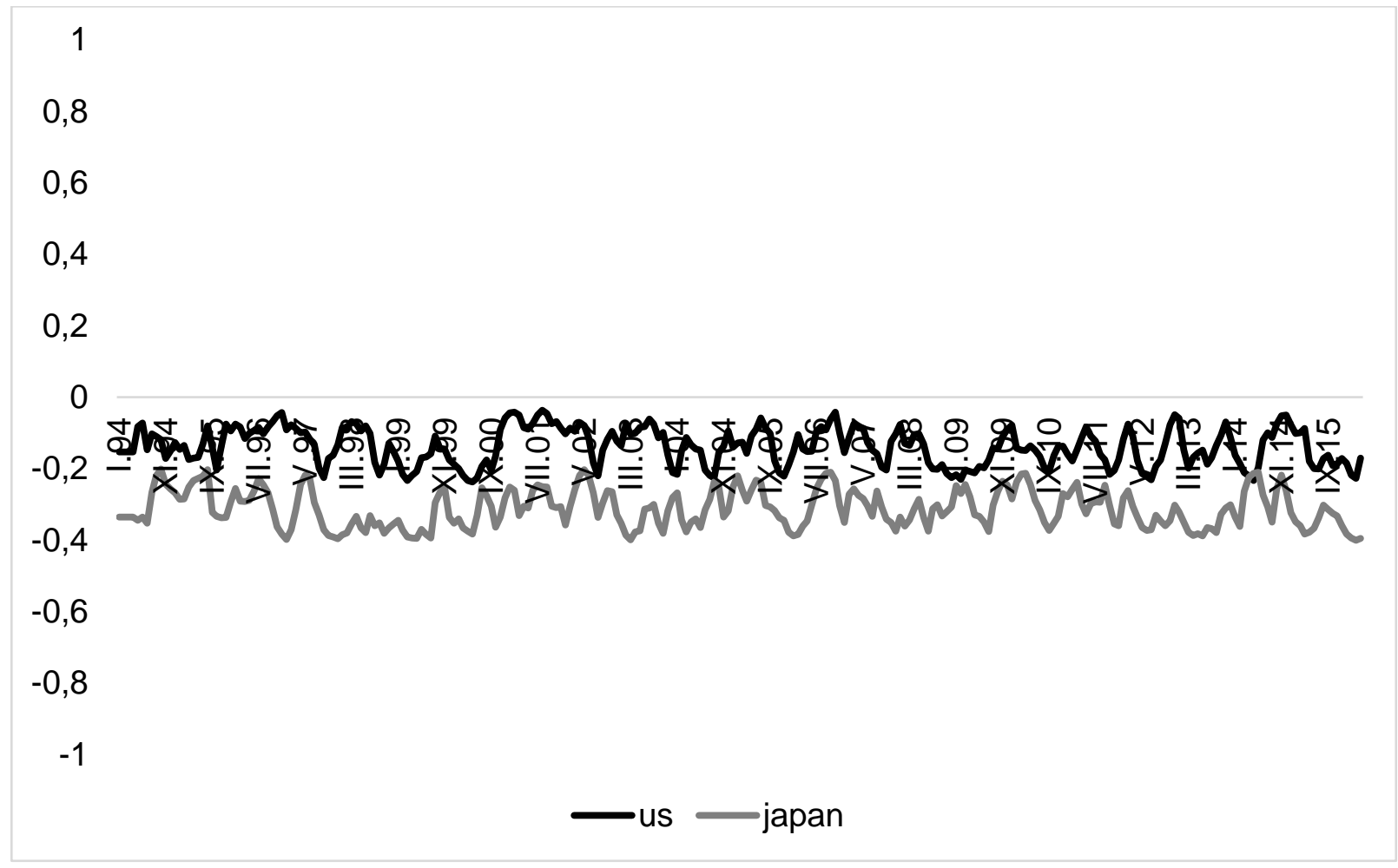


Figure 4.4: The Dynamic Conditional Correlation (1st Difference, Tse and Tsui)

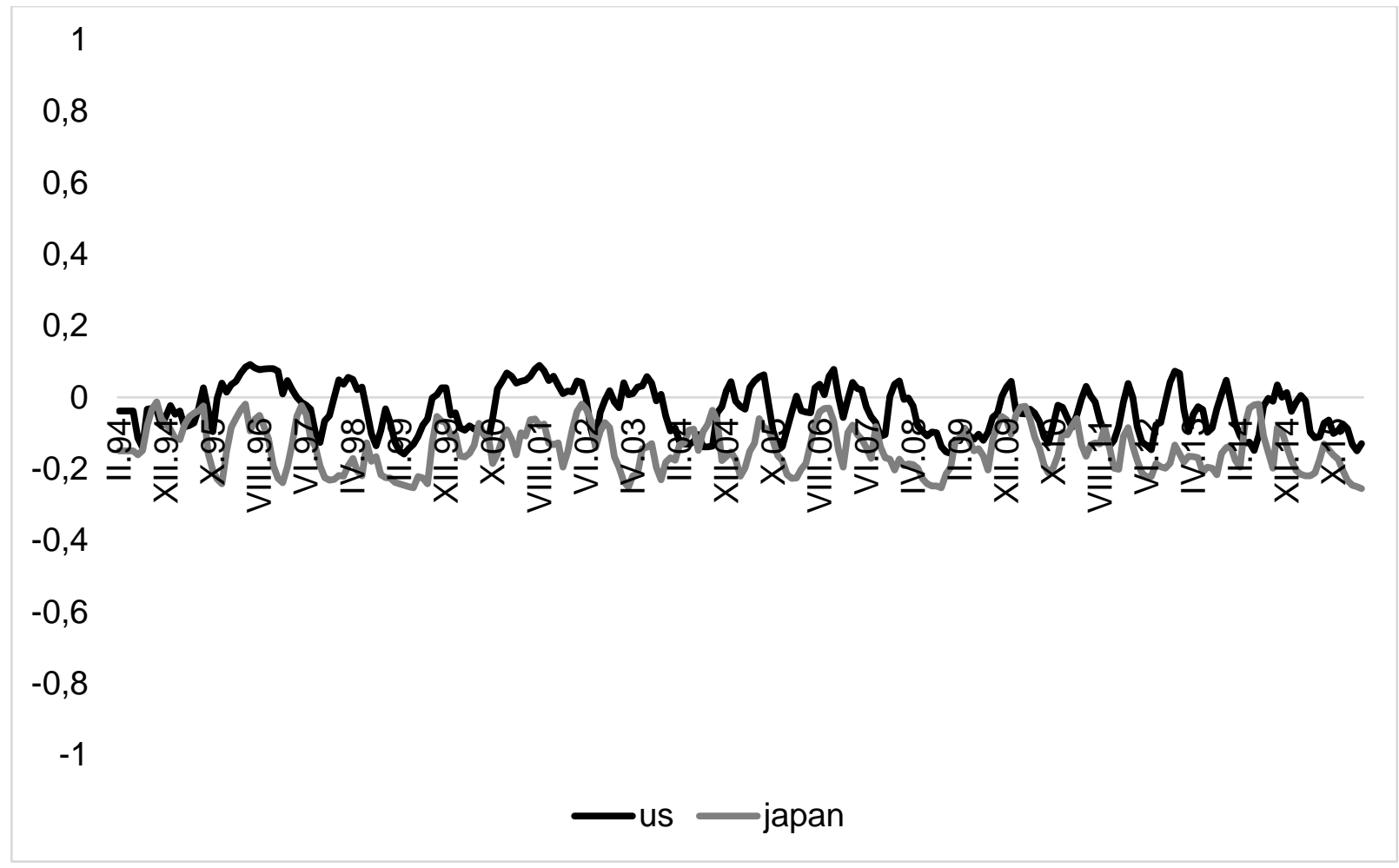

Source: Own Calculation

\section{What Drives the Evolutions of the Dynamic Conditional Correlations}

The dynamic conditional correlations between the level of the exchange rate and the EPU indexes exhibit erratic behavior over the sample period. The estimated correlations are neither consistently positive nor negative for both of the indexes. The exchange rate and the uncertainty indexes are sometimes closely correlated and at other times not. A question is what determines the signs and magnitude of the correlation coefficients. 
Figure 5: VIX@ and the Recession Indicators

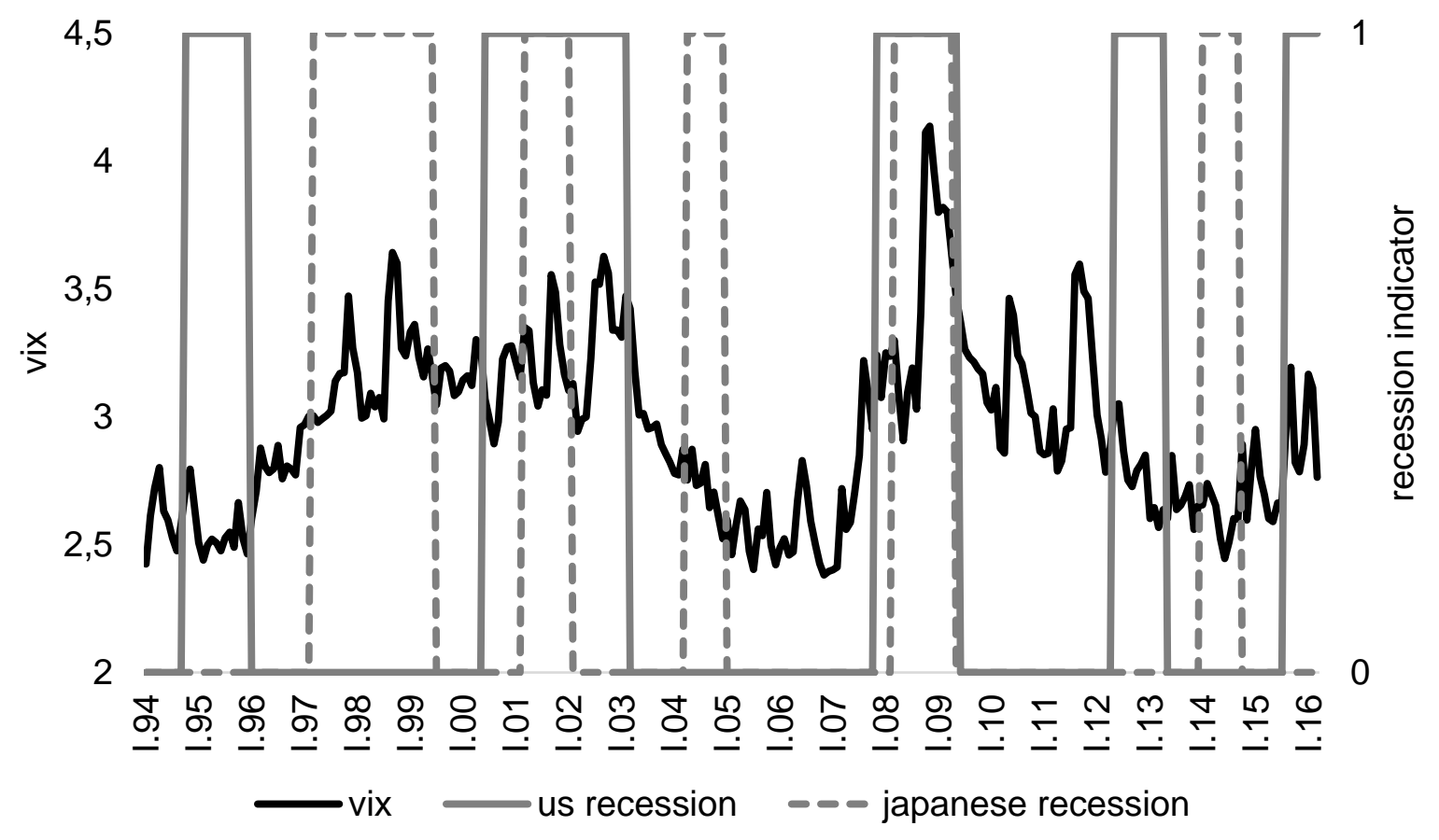

Source: The FRED of the Federal Reserve Bank of St. Louis and OECD Composite Leading Indicators

Table 4: Descriptive Statistics for VIX@

Source: Own Calculation

\begin{tabular}{l|l}
\hline & $\mathrm{VIX}$ \\
\hline Minimum & 2.3812 \\
\hline Mean & 2.9474 \\
\hline Maximum & 4.1374 \\
\hline $\begin{array}{l}\text { Standard } \\
\text { Deviation }\end{array}$ & 0.3419 \\
\hline
\end{tabular}

In order to investigate what drives the evolutions of the dynamic conditional correlations, the following regressions are estimated for each of the dynamic correlations:

$$
\log \left(\frac{1+\hat{\rho}_{i i t, t}}{1-\widehat{\rho}_{i i t}}\right)=\alpha+\beta_{1} y_{1, t}+\beta_{2} y_{2, t}+\beta_{3} v i x_{t}+\beta_{4} D_{u s, t}+\beta_{5} D_{j a p a n, t}+\varepsilon_{t}
$$

for $\mathrm{i}=1$ and 2, where vixt is the log of the monthly average of the Chicago Board of Exchange (CBOE) volatility index (VIX $\odot), D_{u s, t}$ and $D_{\text {japan }, t}$ are indicators that equal 1 if the US and Japanese economies are in recession, $\varepsilon_{t}$ is an error term at time $t$, and $\alpha$ and $\beta$ 's are fixed coefficients. The dependent variable is the Fisher-transformed time-varying correlation coefficients that are estimated in the DCC models. The regression (4) is specified with these explanatory variables under the assumption that the time-varying 
correlations evolve over time, reflecting policy uncertainty and underlying economic conditions.

VIX (C) is the daily series that measures the market expectation of near term volatility conveyed by stock index option prices. The daily series is sourced from the FRED database of the Federal Reserve Bank of St. Louis. The volatility index is assumed to reflect overall economic uncertainty. In the literature, some studies, such as Bloom $(2009,2014)$ and Baker et al. (2013), use VIX (C) to measure economic uncertainty in the United states while others, such as Forbes and Warnock (2012) and Gourinchas and Rey (2013), apply it to gauge global uncertainty. The recessions indicators are based on the Organization of Economic Development (OECD) Composite Leading Indicators, which identify the months of the peaks and troughs of business cycles. The chronology of the peaks and troughs is obtained from OECD ${ }^{5}$. Figure 5 plots the monthly average for VIX (C) and the recession indicators during the sample period. Table 4 provides descriptive statistics of VIX (C) in logarithm.

Table 5 presents the ordinary least squares (OLS) estimates of the regressions. The low values of the adjusted $R^{2}$ indicate that the evolutions of the correlations are largely determined by factors not specified in the regression. The US uncertainty index have quantitatively and statistically significant effects on the dynamic correlations between the exchange rate and the US index, and the estimated coefficient of the regression is negative. That is, the US uncertainty is more likely to lower the US dollar vis-à-vis the Japanese yen if the US uncertainty index is at a higher level. The US index also has unexpected negative impacts on the correlations of the Japanese index. Some of the estimated coefficients of the recessions indicators are statistically significant. The other explanatory variables do not have quantitatively and statistically significant effects on the dynamic correlations.

\section{Table 5: The Regression Analysis}

\section{The US Index, Engle Model}

\begin{tabular}{lllllll}
\hline & $\alpha$ & $\beta 1$ & $\beta 2$ & $\beta 3$ & $\beta 4$ & $\beta 5$ \\
\hline estimate & 1.2929 & -0.5579 & 0.1512 & 0.1240 & 0.0554 & 0.1637 \\
\hline standard error & 0.3012 & 0.0727 & 0.0615 & 0.0682 & 0.0399 & 0.0441 \\
\hline t-value & 4.2932 & -7.6748 & 2.4592 & 1.8173 & 1.3879 & 3.7119 \\
\hline & & Adjusted R Squared & 0.2442
\end{tabular}

${ }^{5}$ stats.oecd.org. 
The Japanese Index, Engle Model

\begin{tabular}{lllllll}
\hline & $\alpha$ & $\beta 1$ & $\beta 2$ & $\beta 3$ & $\beta 4$ & $\beta 5$ \\
\hline estimate & 1.769 & -0.398 & -0.058 & -0.033 & 0.350 & -0.087 \\
\hline standard error & 0.340 & 0.082 & 0.070 & 0.077 & 0.045 & 0.050 \\
\hline t-value & 5.197 & -4.846 & -0.833 & -0.425 & 7.771 & -1.740 \\
\hline \multicolumn{5}{r}{ Adjusted R Squared } & 0.2300
\end{tabular}

The US Index, Tse and Tsui Model

\begin{tabular}{lllllll}
\hline & $\alpha$ & $\beta 1$ & $\beta 2$ & $\beta 3$ & $\beta 4$ & $\beta 5$ \\
\hline estimate & 0.6075 & -0.2016 & 0.0796 & -0.0314 & 0.0515 & -0.0071 \\
\hline standard error & 0.1393 & 0.0336 & 0.0284 & 0.0316 & 0.0185 & 0.0204 \\
\hline t-value & 4.3600 & -5.9956 & 2.7993 & -0.9943 & 2.7908 & -0.3479 \\
\hline \multicolumn{5}{c}{ Adjusted R Squared } & 0.1609
\end{tabular}

The Japanese Index, Tse and Tsui Model

\begin{tabular}{lllllll}
\hline & $\alpha$ & $\beta 1$ & $\beta 2$ & $\beta 3$ & $\beta 4$ & $\beta 5$ \\
\hline estimate & 0.607 & -0.202 & 0.080 & -0.031 & 0.0515 & -0.007 \\
\hline standard error & 0.139 & 0.034 & 0.028 & 0.032 & 0.0185 & 0.020 \\
\hline $\mathrm{t}$-value & 4.360 & -5.996 & 2.799 & -0.994 & 2.7908 & -0.348 \\
\hline & & \multicolumn{5}{c}{ Adjusted R Squared }
\end{tabular}

Source: Own Calculation

\section{$6 \quad$ Concluding Remarks}

This study has applied the multivariate DCC-GARCH models to analyze the time-varying effects of policy uncertainty on the US / Japan foreign exchange rate. It has found that the dynamic conditional correlations between the EPU indexes and the exchange rate are not time-invariant. For the level of the exchange rate, in particular, the sign of the correlation changes in the sample period.

One can speculate on economic reasons behind the correlations that the statistical models have found in this study. In the late 1990s, the Japanese yen depreciated vis-à-vis the US dollar. The analysis above has found that the exchange rate was positively correlated with the US EPU index and negatively with the Japanese index. During this period of time, the Japanese economy plunged into a severe slump and the Japanese EPU index sharply rose while the US economy experienced steady growth under the Clinton administration. The correlations reflect these contrasting political and economic conditions between the two countries.

After the Global Financial Crisis of 2007-08, the exchange rate was negatively correlated with the US and Japanese EPU indexes. The Crisis hit the world economy, and the EPU indexes of the United States and Japan both rose and remained high. The Crisis, however, started in the subprime 
housing market of the United States, and the value of the US dollar depreciated relative to the Japanese yen (and other major currencies). The negative correlations reflect the more turbulence in the United States.

Some regression analyses also have been performed to investigate what determine the sign and magnitude of the dynamic correlations between policy uncertainty and the level of the exchange rate. The US policy uncertainty has negative effects on the correlations. That is, the policy uncertainty in the United States is more likely to lower the value of the US dollar vis-à-vis Japanese yen if the uncertainty index is higher. Some of the recession indicators also have quantitatively and statistically significant effects on the correlations. A large fraction of the driving force of the correlations is, however, attributed to unknown random factors in the regression.

In concluding, the limitations of this study should be borne in mind. In this study, the EPU index has been used as a proxy variable for policy uncertainty. The index is, however, not a direct measure of policy uncertainty. In particular, the Japanese EPU index is still the "beta" nature, drawing only upon newspaper coverage. Thus, it cannot be denied that the index is a weak proxy meausring other risk factors. These limitations should be overcome through methodological improvements in further studies.

\section{References}

Aisen, A., and Veiga, F. J. (2013) How does political instability affect economic growth?. European Journal of Political Economy, 29, 151-167.

Alexopoulos, M., and Cohen, J. (2015) The power of print: Uncertainty shocks, markets, and the economy. International Review of Economics \& Finance, 40, 8-28.

Antonakakis, N.; Chatziantoniou, I. and Filis, G. (2013) Dynamic co-movements of stock market returns, implied volatility and policy uncertainty. Economics Letters, 120(1), 87-92.

Antonakakis, N.; Gupta, R., and André, C. (2015) Dynamic co-movements between economic policy uncertainty and housing market returns. Journal of Real Estate Portfolio Management, 21(1), 53-60.

Baker, S. R., and Bloom, N. (2013) Does uncertainty reduce growth? Using disasters as natural experiments (No. w19475). National Bureau of Economic Research.

Baker, S. R.; Bloom, N.; Davis, S. J. (2016) Measuring economic policy uncertainty (No. w21633). National Bureau of Economic Research.

Balcilar, M.; Gupta, R. and Jooste, C. (2014) The Role of Economic Policy Uncertainty in Forecasting US Inflation Using a VARFIMA Model. Department of Economics, University of Pretoria, Working Paper No, 201460.

Balcilar, M., Gupta, R., Kyei, C. and Wohar, M. E. (2016) Does Economic Policy Uncertainty Predict Exchange Rate Returns and Volatility? Evidence from a Nonparametric Causality-in-Quantiles Test. Open Economies Review,27(2), 229-250.

Balcilar, M.; Gupta, R. and Segnon, M. (2015) The role of economic policy uncertainty in predicting US recessions: A mixed-frequency Markov-switching vector autoregressive approach. Department of Economics, University of Pretoria, Working Paper No, 20158.

Boudoukh, J.; Feldman, R. and Kogan, S., \& Richardson, M. (2013) Which news moves stock prices? a textual analysis (No. w18725). National Bureau of Economic Research. 
Bloom, N. (2009) The impact of uncertainty shocks. econometrica, 77(3), 623-685.

Bloom, N. (2014) Fluctuations in uncertainty. The Journal of Economic Perspectives, 28(2), 153-175.

Dufour, J. M. and Roy, R. (1985) Some robust exact results on sample autocorrelations and tests of randomness. Journal of Econometrics, 29(3), 257-273.

Dufour, J. M. And Roy, R. (1986) Generalized portmanteau statistics and tests of randomness. Communications in Statistics-Theory and Methods, 15(10), 2953-2972.

Engle, R. F. (1982) Autoregressive conditional heteroscedasticity with estimates of the variance of United Kingdom inflation. Econometrica: Journal of the Econometric Society, 987-1007.

Engle, R. (2002) Dynamic conditional correlation: A simple class of multivariate generalized autoregressive conditional heteroskedasticity models. Journal of Business \& Economic Statistics, 20(3), 339-350.

Forbes, K. J. and Warnock, F. E. (2012) Capital flow waves: Surges, stops, flight, and retrenchment. Journal of International Economics, 88(2), 235-251.

Gentzkow, M., and Shapiro, J. M. (2010) What drives media slant? Evidence from US daily newspapers. Econometrica, 78(1), 35-71.

Gourinchas, P. O. and Rey, H. (2013). External adjustment, global imbalances and valuation effects (No. w19240). National Bureau of Economic Research.

Hoberg, G., and Phillips, G. (2010) Product market synergies and competition in mergers and acquisitions: A text-based analysis. Review of Financial Studies,23(10), 3773-3811.

Jones, P. M., and Olson, E. (2013) The time-varying correlation between uncertainty, output, and inflation: Evidence from a DCC-GARCH model.Economics Letters, 118(1), 33-37.

Krol, R. (2014) Economic policy uncertainty and exchange rate volatility.International Finance, 17(2), 241256.

Ljung, G. M. and Box, G. E. (1978) On a measure of lack of fit in time series models. Biometrika, 65(2), 297303.

MacDonald, R. and Marsh, I. (2013) Exchange rate modelling (Vol. 37). Springer Science \& Business Media.

Martin, J. A. J. and Urrea, R. P. (2011) The Effects Of Macroeconomic And Policy Uncertainty On Exchange Rate Risk Premium. International Business \& Economics Research Journal (IBER), 6(3).

Tsay, R. S. (2013) Multivariate time series analysis: with $R$ and financial applications. John Wiley \& Sons.

Tse, Y. K. and Tsui, A. K. C. (2002) A multivariate generalized autoregressive conditional heteroscedasticity model with time-varying correlations. Journal of Business \& Economic Statistics, 20(3), 351-362.

Volcker, P., and Gyoten, T. (1992) Change of Fortune. 